\title{
Development of an intervention to facilitate implementation and uptake of diabetic retinopathy screening
}

\author{
Fiona Riordan ${ }^{1 *}$, Emmy Racine ${ }^{1}$, Eunice T. Phillip ${ }^{1}$, Colin Bradley², Fabiana Lorencatto ${ }^{3}$, Mark Murphy ${ }^{4}$, \\ Aileen Murphy ${ }^{5}$, John Browne ${ }^{1}$, Susan M. Smith ${ }^{4}$, Patricia M. Kearney ${ }^{1}$ and Sheena M. McHugh ${ }^{1}$
}

\begin{abstract}
Background: 'Implementation interventions' refer to methods used to enhance the adoption and implementation of clinical interventions such as diabetic retinopathy screening (DRS). DRS is effective, yet uptake is often suboptimal. Despite most routine management taking place in primary care and the central role of health care professionals (HCP) in referring to DRS, few interventions have been developed for primary care. We aimed to develop a multifaceted intervention targeting both professionals and patients to improve DRS uptake as an example of a systematic development process combining theory, stakeholder involvement, and evidence.

Methods: First, we identified target behaviours through an audit in primary care of screening attendance. Second, we interviewed patients $(n=47)$ and HCP $(n=30)$, to identify determinants of uptake using the Theoretical Domains Framework, mapping these to behaviour change techniques (BCTs) to develop intervention content. Thirdly, we conducted semi-structured consensus groups with stakeholders, specifically users of the intervention, i.e. patients $(n=15)$ and HCPs $(n=16)$, regarding the feasibility, acceptability, and local relevance of selected BCTs and potential delivery modes. We consulted representatives from the national DRS programme to check intervention 'fit' with existing processes. We applied the APEASE criteria (affordability, practicability, effectiveness, acceptability, side effects, and equity) to select the final intervention components, drawing on findings from the previous steps, and a rapid evidence review of operationalised BCT effectiveness.
\end{abstract}

Results: We identified potentially modifiable target behaviours at the patient (consent, attendance) and professional (registration) level. Patient barriers to consent/attendance included confusion between screening and routine eye checks, and fear of a negative result. Enablers included a recommendation from friends/family or professionals and recognising screening importance. Professional barriers to registration included the time to register patients and a lack of readily available information on uptake in their local area/practice. Most operationalised BCTs were acceptable to patients and HCPs while the response to feasibility varied. After considering APEASE, the core intervention, incorporating a range of BCTs, involved audit/feedback, electronic prompts targeting professionals, HCP-endorsed reminders (face-to-face, by phone and letter), and an information leaflet for patients.

\footnotetext{
* Correspondence: fiona.riordan@ucc.ie

'School of Public Health, University College Cork, Western Gateway Building, Western Rd, Cork, Ireland

Full list of author information is available at the end of the article
}

(c) The Author(s). 2020 Open Access This article is licensed under a Creative Commons Attribution 4.0 International License, which permits use, sharing, adaptation, distribution and reproduction in any medium or format, as long as you give appropriate credit to the original author(s) and the source, provide a link to the Creative Commons licence, and indicate if changes were made. The images or other third party material in this article are included in the article's Creative Commons licence, unless indicated otherwise in a credit line to the material. If material is not included in the article's Creative Commons licence and your intended use is not permitted by statutory regulation or exceeds the permitted use, you will need to obtain permission directly from the copyright holder. To view a copy of this licence, visit http://creativecommons.org/licenses/by/4.0/. The Creative Commons Public Domain Dedication waiver (http://creativecommons.org/publicdomain/zero/1.0/) applies to the data made available in this article, unless otherwise stated in a credit line to the data. 
(Continued from previous page)

Conclusions: Using the example of an intervention to improve DRS uptake, this study illustrates an approach to integrate theory with user involvement. This process highlighted tensions between theory-informed and stakeholder suggestions, and the need to apply the Theoretical Domains Framework (TDF)/BCT structure flexibly. The final intervention draws on the trusted professional-patient relationship, leveraging existing services to enhance implementation of the DRS programme. Intervention feasibility in primary care will be evaluated in a randomised cluster pilot trial.

Keywords: Retinal Screening, Family Practitioner, Implementation Intervention, Intervention development, Theoretical Domains Framework, Patient and Public Involvement (PPI), Stakeholder consultation

\section{Contributions to the literature}

- Interventions to improve DRS uptake demonstrate wide heterogeneity in effectiveness and limited use of explicit behaviour change strategies.

- Although routine management of type 2 diabetes largely takes place in primary care, few interventions have focused on primary care, and targeted both professionals and patients.

- Few studies explicitly document the process of user involvement and how it influences intervention content and delivery.

- To address these gaps, we adopted an explicit process of involving intervention users (professionals and people with diabetes) and developed an intervention for delivery in primary care, clearly outlining our development process which combines behaviour change theory, stakeholder involvement, and existing evidence of intervention effectiveness.

\section{Background}

The number of people with diabetes is rising globally, placing a burden on health systems, people with diabetes, and their families [1]. Diabetic retinopathy (DR) is the most common microvascular complication of diabetes [2, 3]. Worldwide, it is estimated that approximately 28 million individuals have vision-threatening retinopathy [4]. In Ireland, DR affects $8.2 \%$ of the population with type 2 diabetes over 50 years (approximately 10,000 people) [5] and is one of the leading causes of blindness among adults of working age [6]. Regular diabetic retinopathy screening (DRS) leads to the earlier detection of retinopathy and treatment that can prevent or delay the development of diabetes-related blindness [79]. In most countries that have screening programmes, DRS is recommended annually [10-12].

Although DRS is found to be effective, uptake is often suboptimal [13-18]. In Ireland, RetinaScreen provides free, annual retinal screening (and if necessary, treatment) to anyone aged 12 years or older with diagnosed diabetes. Uptake of this government-funded populationbased DRS programme, introduced in 2013, is currently $56 \%$ [19]. In the international literature, non-attendance at screening has been linked to a number of factors including younger age $[14,16]$, lower socioeconomic status (SES) [20-23], longer diabetes duration, type of diabetes (people with type 1 are less likely to attend) [20], and poorer glycaemic control [24]. Barriers include a lack of awareness of DR and the risk of retinopathy [24, 25], the accessibility of screening centres, and time constraints [25]. Recommendation to attend screening from a primary care health care professional (primary care HCP) encourages attendance [24-26].

'Implementation interventions' refer to methods used to enhance the adoption and implementation of clinical interventions such as DRS [27]. To be most effective, implementation interventions should target multiple levels [28-31]: (1) introducing system-level change to facilitate sustainability and integration with existing infrastructure, (2) providing support to health care professionals to change work practices, and (3) targeting, or intervening with, patients to change behaviours and outcomes [32]. Type 2 diabetes, which accounts for about $90 \%$ of all cases of diabetes [33], is largely managed in primary care, so it is an appropriate setting in which to introduce implementation interventions to target DRS uptake. Primary care HCPs have a role in referring to DRS services and promoting attendance. It also presents an opportunity to target patients who have stopped attending specialist care (e.g. type 1) who may have poorer diabetes control and thus be at higher risk of complications such as retinopathy [34]. Despite this, few interventions have focussed on primary care [13] and targeted both professionals and patients [13, 35-39].

Successful interventions to improve DRS uptake [4042] include patient education to increase awareness of DR [35, 43, 44], patient reminders [13, 36, 37, 39, 4553], guidelines [35], education [36, 37], or registration and reminder systems to support professionals to 
follow-up patients [13, 37-39, 41, 54]. However, a recent Cochrane review found that while interventions target some important barriers, they incorporate a narrow range of behaviour change techniques, with 'missed opportunities' to target some of the individual, social, cultural, and environmental barriers and enablers of screening attendance [55]. In addition, the effects of interventions vary widely, and this variation remains largely unexplained [40]. Few studies are explicit in terms of the frameworks and theories used to guide intervention development $[13,44,56]$. Therefore, DRS is one clinical service which would benefit from a more systematic, theory-based approach to improve implementation.

There is ongoing uncertainty about the best approach to develop and tailor interventions [30, 57, 58]. Despite mixed evidence on the contribution of theory to intervention effectiveness $[59,60]$, it is a central part of many approaches to developing interventions. User involvement is recommended as another key component [61, 62] to tailor the content of interventions to context (i.e. primary care setting) [30] and align with stakeholder preferences [63]. Despite recognition that these elements are important, the challenge is how to combine these elements, for example, it is often unclear how development moves from theory to decisions about intervention content, format, and delivery, and what role stakeholders play in this step [64]. There is a need for case examples which clearly outline all steps of the development process, in particular how to utilise theory while also eliciting and integrating the perspectives of end users, drawing on elements of coproduction.

\section{Aim}

Our aim was to use a systematic process combining theory, stakeholder involvement, and existing evidence of the effectiveness of interventions, to develop a multifaceted implementation intervention targeting both primary care HCPs and patients to improve the update of DRS. A broader aim of this paper is to provide a case study of how to systematically develop an implementation intervention drawing on both theory and stakeholder involvement, and to highlight some of the challenges and lessons inherent in this approach.

\section{Methods \\ Design}

The IDEAs (Improving Diabetes Eye screening Attendance) intervention was developed by combining theory, stakeholder involvement, and evidence [58, 65]. By stakeholders, we mean people with diabetes, professionals, and representatives from the national screening programme. We drew on the principles of co-creation, defined by Leask et al. as 'collaborative public health intervention development by academics working alongside other stakeholders' [66], along with the INVOLVE definitions of collaboration 'an ongoing partnership between you and the members of the public you are working with, where decisions about the research are shared', and consultation 'when you ask members of the public for their views and use these views to inform your decision-making' [67]. Stakeholder involvement was part of an overall effort to co-create the intervention; specifically, involvement comprised collaboration with HCPs and patients (users of the intervention) over the course of the development process, and consultation with representatives from the national screening programme to ensure integration of intervention components with existing processes.

The core intervention development work took place in $2018 / 2019$ when the national screening programme had begun to introduce new approaches to facilitate participation [68]. This stepped systematic development process [65] has been used to develop implementation interventions in different settings $[69,70]$ (Fig. 1). The final intervention was reported according to guidance from TiDieR [71] and Proctor et al. [27].

\section{Step 1: Identify who needs to do what, differently}

DRS involves a number of potential different behaviours being performed by different individuals. We therefore aimed to identify which behaviours to target by analysing data from an existing audit of screening uptake in two large primary care centres in the South of Ireland [68].

\section{Step 2: Identify the barriers and enablers to be addressed using theoretical frameworks}

To identify barriers and enablers, we analysed existing qualitative data collected as part of a study to understand patient and professional experiences of DRS among other diabetes services. Patient interviews were conducted by MT (July 2014 and January 2015) (see "Acknowledgements"). Participants were purposively sampled from the list of audited patients according to screening status (i.e. attenders, non-attenders, nonconsenters) defined according to the audit. Participants were not sampled by other demographic factors. Patient interviews were conducted at the two primary care centres [72]. A semi-structured interview guide was used to explore patient knowledge of diabetes and DR and their history of attending existing DRS services and experience of RetinaScreen, including the reasons for deciding to participate (or not) in the new programme (Additional file 1).

$\mathrm{HCP}$ interviews and focus groups were conducted by FR and KON (PhD researchers in the team at the timesee "Acknowledgements") between April 2016 and 


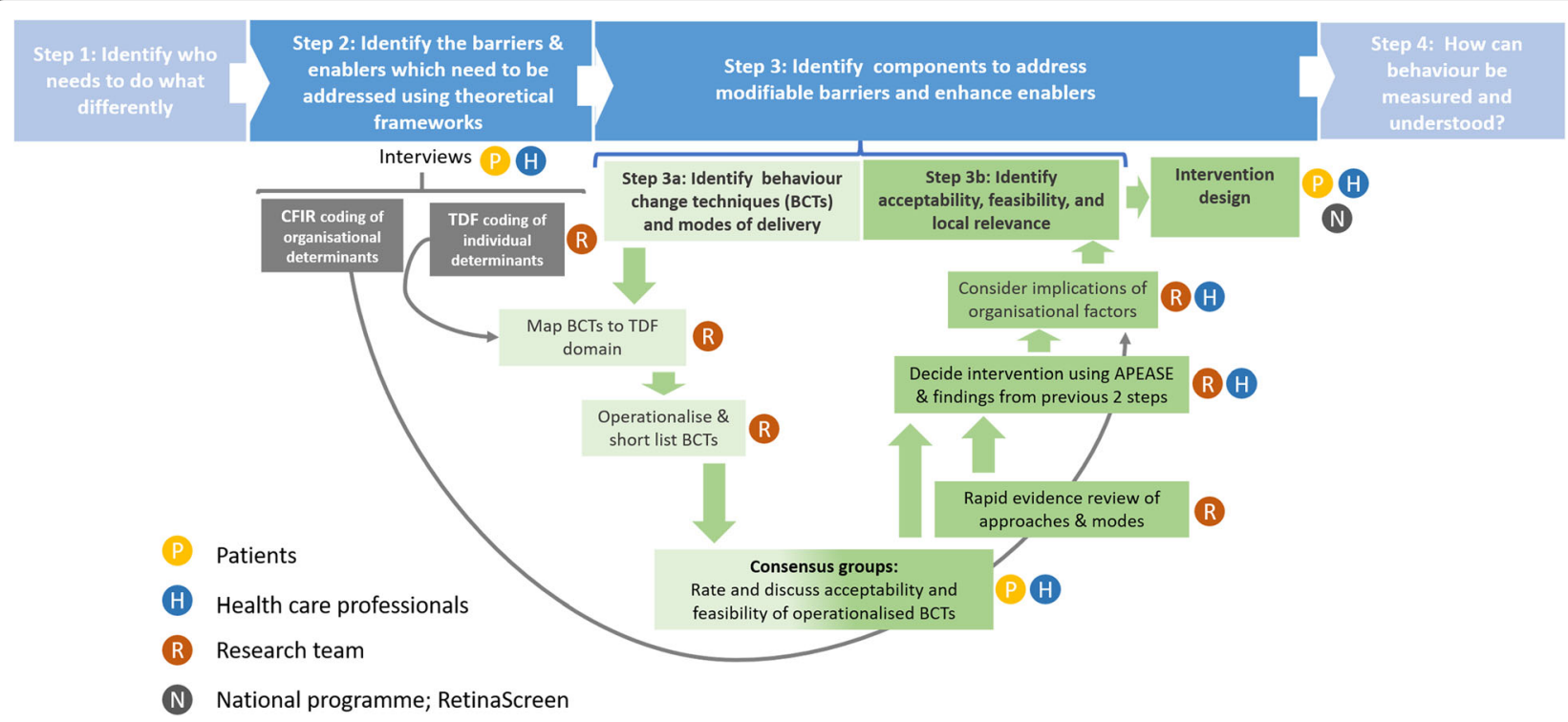

Fig. 1 Overview of the development process. TDF, Theoretical Domains Framework; DRS, Diabetic Retinopathy Screening; BCT, behaviour change technique; CFIR, Consolidated Framework for Implementation Research

February 2017. HCP participants were purposively sampled according to their role and region of Ireland, not other demographic factors. Interviews with GPs, PNs, and DNS were conducted in a mix of general practices across Ireland (GPs, PNs), health administrative offices (DNS), and hotels (DNS) to coincide with professional conferences. HCP interviews were conducted as part of a broader realist evaluation to understand the implementation of the national clinical programme for diabetes, including the establishment of a national DRS programme [73]. As such, the topic guide was informed by attendance patterns and initial theories about how the DRS programme was working. It also included open questions to elicit HCPs' experiences of engaging with the national DRS programme, for example, barriers to, and facilitators of, the registration process (Additional file 1). Interviews were digitally recorded, transcribed verbatim, and imported into NVivo 10 software for analysis.

The analytical approach for this intervention development study did not follow the principles of realist analysis. Instead, the deductive analysis was directed by the Theoretical Domains Framework (TDF) and informed by a coding structure developed as part of a recent systematic review of screening attendance (Additional file 2: Table S1) [25] which was used to code interviews to identify the barriers and enablers to the target behaviours and to guide the choice of intervention components [74]. In instances where a single TDF domain did not apply, multiple domains were applied. Barriers and enablers were compared with those identified in the systematic review [75]. Two members of the research team (FR and SMH) prioritised factors which were identified in both international and Irish contexts, and the Irish context only, and focused on modifiable factors, i.e. those which would be possible to address through an intervention delivered through primary care. Non-modifiable factors (i.e. system-level factors which were beyond the scope of this primary care intervention) were shared with the national programme stakeholders.

The Consolidated Framework for Implementation Research (CFIR) was also used to code the HCP interviews to ensure organisational level influences were thoroughly considered, specifically, to identify if they could be targeted by the intervention or to identify non-modifiable factors which might act as wider implementation determinants. These determinants of uptake were considered during the next step of the development process.

\section{Step 3: Identify and decide the intervention components to address modifiable barriers and enhance enablers}

3 (a) Identify behaviour change techniques and modes of delivery Barriers and enablers, grouped by theoretical domains, were mapped to appropriate behaviour change techniques (BCTs). The mapping process was based on published expert consensus about effectiveness for behaviour change $[76,77]$ and a 'TDF matrix' constructed by Lawrenson et al. as part of their Cochrane review of interventions to improve DRS 
uptake [40]. The matrix links BCTs to TDF domains, indicating which techniques are likely to be effective in changing that particular domain. The mapping process resulted in a long list of potential BCTs for the intervention.

The initial long list of BCTs was narrowed down based on whether the technique had been shown in other studies to be effective as part of interventions to increase DRS [40] or if there was evidence in the wider literature on public health interventions of effectiveness of the technique in other settings (e.g. smoking cessation, interventions to improve diet and exercise). BCTs were retained if specific examples of how to operationalise them to improve DRS uptake were available $[40,55]$.

Operationalised BCTs were further refined following review by members of the research team (FR, SMH, SMS, PMK, JB, AM) together with the expert input of a behavioural scientist (FL), while also considering the scope of the current study, and non-modifiable organisational factors. For example, operationalised BCTs completely beyond the scope of the study, such as ones requiring changes to the operation of the national retinopathy screening programme were excluded at this point. Remaining BCTs were revisited to ensure we had at least included ones which corresponded to salient TDF domains, that is those frequently mentioned and/or deemed to be of high importance by the researchers or participants.

3 (b) Identify feasibility, local relevance, and acceptability of the intervention

\section{Consensus groups}

Three semi-structured consensus group meetings were held with people with diabetes (meeting 1), people with diabetes and HCP (meeting 2), and HCP only (meeting 3) to discuss the feasibility of proposed intervention components (operationalised BCTs) and suitable modes of delivery. Further details on the consensus group meetings, including recruitment of patients and members of the public, are provided as part of a SWAT (Study Within A Trial) which observed group dynamics and gathered data on participants' experiences of the meetings [78]. Before the meetings, participants were given a short summary of evidence on barriers and enablers of DRS attendance and approaches to address non-attendance. Participants were also sent an electronic or paper survey, to assess feasibility and acceptability, based on a validated instrument developed by Weiner et al. [79] (Additional file 3). Participants were asked to rate the acceptability and feasibility of each component on a five-point Likert scale ranging from 'strongly disagree' to 'strongly agree'. Consensus meetings were facilitated by an experienced facilitator (JB). During the meetings, a summary of the survey results was presented to participants followed by a series of small group discussions facilitated by FR, SMH, and EP. Participants were asked to consider how each component would work in practice and which mode of delivery would work best.

\section{Populating the APEASE criteria}

The final components were decided by a subgroup of the research team (FR, SMH, PMK, SMS) and a GP collaborator (MM) based on the APEASE (affordability, practicability, effectiveness, acceptability, side effects, equity, sustainability) criteria. Acceptability and practicability criteria were populated with findings from consensus meetings using a process informed by previous studies which utilised consensus methods [80] (Table 1). The effectiveness criterion was based on a rapid evidence review of different approaches to improve screening (e.g. text/letter/phone reminders and messages, educational materials, brief interventions and narrative leaflets) (see Additional file 4: PubMed search strategy). The remaining criteria were based on group discussions among the subgroup of research team and GP collaborator.

After this, the research team deliberated on the available evidence for each shortlisted component and the proposed mode of delivery. We considered organisational factors identified through patient interviews (i.e. at the level of the screening programme), and $\mathrm{HCP}$ interviews (i.e. at the level of the practice) coded using CFIR. If non-modifiable, the team considered how best to work around/with this factor to help the fit of the intervention components within the primary care environment. Following a decision on the final intervention components, RetinaScreen were

Table 1 Overview of the shortlisting process

If $\geq 70 \%$ of participants agreed* the component was acceptable it was retained.

If $<70 \%$ of participants agreed the component was acceptable:

(1) If all three groups discussed the component in the meetings...

- If all were either, unsure whether it was feasible or felt it was unfeasible or unacceptable then it was excluded.

- If two groups felt it was feasible and one did not then this component was considered.

- If only one group felt it was feasible then this component was excluded. (2) If only two groups discussed the component...

- If one group felt it was unfeasible or unacceptable and the other did not then group composition was considered. For example, if professionals in the mixed group or professional-only group expressed concerns about feasibility, then this was given more weight than if concern was expressed by people with diabetes felt the component was feasible in primary care.

(3) If only one or no groups discussed the component...

- If $<70 \%$ participants agreed it was feasible then this component was excluded. If $\geq 70 \%$ agreed it was feasible then this component was included.

* Survey response categories were collapsed into 'Agree', 'Neither agree nor disagree' and 'Disagree' 
consulted to determine whether additional modifications were needed. Intervention study materials were prepared by a graphic designer, reviewed by the National Adult Literacy Agency (NALA) and a Patient and Public Involvement (PPI) group established to incorporate additional patient involvement in developing the intervention materials and advise on the study procedures on an ongoing basis. Materials were subsequently revised to include their suggestions.

\section{Step 4: How can behaviour change be measured and understood?}

A logic model of the final IDEAs intervention, representing the inputs, processes, and the causal mechanisms by which it is expected to achieve change was developed, in conjunction with deciding the feasibility of outcome measures for the pilot trial.

Ethical approval was obtained from the Clinical Research Ethics Committee for the Cork Teaching Hospitals.

\section{Results}

Step 1: Identify who needs to do what, differently

The audit findings highlighted suboptimal uptake and distinguished gaps at the level of the professional and patient, specifically, registration with the programme (professional), consent for the programme to hold their contact details and send them an appointment letter (patient), and attendance once they received their appointment (patient) [68]. Hence, it was decided the intervention should target both people with diabetes and professionals.

Step 2: Identify the barriers and enablers to be addressed using theoretical frameworks

In addition to the 47 patient interviews (Additional file 5: Table S2), 22 interviews were conducted with (GPs $(n=5)$, practice nurses $(n=9)$, and DNS $(n=$ $8)$, and 2 focus groups (4 per group) were conducted with community DNS $(n=8)$.

Examples of barriers for patients included confusion between screening and routine eye checks ('Knowledge'), forgetting ('Memory, attention, decision processes'), and anticipation of a negative result ('Beliefs about consequences'). Enablers included a recommendation from friends/family or HCPs ('Social Influences'). HCP barriers included the time to register patients which was impeded or supported by practice resources ('Environmental context and resources'). HCPs also lacked information on screening uptake in their local area ('Knowledge'). Modifiable patient and professional-level factors mapped to BCTs are provided in Additional file 6: Table S3 ( $a$ and b).

Several organisational factors, identified both in the interviews and the Cochrane review and classified using CFIR, were not modifiable within the scope of the study and reflected structural and organisational aspects of the screening programme (e.g. accessibility of screening centres, being able to reschedule appointment, competing demands such as getting time off work, presence or absence of media coverage to increase awareness) (Additional file 7: Table S4).

\section{Step 3: Identify and decide intervention components to address modifiable barriers and enhance enablers 3(a) Identify potential behaviour change techniques and modes of delivery}

Selected operationalised BCTs within each domain ( $n$ $=48$ ) were organised according to whether they operate at the patient, professional, or organisational level, i.e. features of the wider practice context which impede or enable professionals to register patients. Some operationalised BCTs deemed to be outside of scope of the study were excluded, for example, sending a congratulatory letter to attendees (requiring the input of RetinaScreen) or supporting patients to develop a plan for how often they will attend screening, where it will take place and how they will get their appointment (requiring extensive input from primary care professionals in a face-to-face consultation). Shortlisted operationalised BCTs are indicated in Additional file 8: Table S5 (a, b and c) along with reasons for exclusion.

\section{3 (b): Identify feasibility, acceptability and local relevance of the intervention}

Consensus groups

In total, 16 patients and $15 \mathrm{HCPs}$, including GPs, practice nurses, diabetes nurse specialists, and an ophthalmologist, took part in the consensus process. Most of the 39 proposed components (operationalised BCTs) were acceptable to $\geq 70 \%$ of participants, while the response to feasibility varied (Additional file 9: Fig. S1). For example, while $80 \%$ of participants felt it would be acceptable to identify someone in the practice to help the patient to register and consent, only $60 \%$ felt this would be feasible.

During consensus meetings, some components were supported across all groups. Providing feedback on screening uptake to practices was considered essential. Delivering reminders and messages through a GP or nurse was favoured, albeit some professionals were uncertain about the feasibility of communicating messages to patients given how 'stretched' resources are in primary care.

I think someone in the practice [should deliver the message], again your GP, with a good solid kind of relationship with your GP, I think you will take more notice of him or her (Patient, Group 1) 
Participants deemed certain components unfeasible or inappropriate. For example, arranging social support was considered a potential breach of confidentiality and only appropriate in some very specific circumstances. In other instances, there were divergent opinions among people with diabetes and HCPs. For example, HCPs believed publicising the numbers who attended at their practice could work for some but not all patients; however, patients disagreed:

If you say, sure $95 \%$ of people go to their screening. Aw sure, I dont need to go so. I don't want to be shamed or I don't want to feel like I am being shamed (Patient, Group 1)

Where groups reflected on the actual content of specific messages, they emphasized the need to avoid 'scare tactics' while also being able to 'dispel a false sense of security'. Participants suggested some system-level changes which were unfeasible within the scope of the current study, for example, provision of alternative opening hours or greater data sharing between RetinaScreen and primary care practices.

\section{Populating the APEASE criteria}

We considered the implications of organisational factors, classified using the TDF and CFIR, integrating this step into our final decision process using APEASE (Table 2). This led us to introduce certain intervention components to accommodate the additional organisational challenges, to encourage participation, aid the roll out of the intervention, and enhance some enablers, but these components were not necessary or core for the intervention to work. For example, reimbursement and technical assistance were added as a new staff resource could not be introduced to conduct the audit. We also included components to mediate the effect of certain nonmodifiable factors (e.g. informing patients about the ease with which they can reschedule their appointment, recognising that patients have competing demands and that out-of-hours screening could not be provided within the study) (Additional file 7: Table S4). We also refined delivery modes at this point. For example, a practice briefing was added as a way to communicate important messages (BCTs) to professionals.

After considering the consensus group findings and evidence of effectiveness, in terms of the APEASE criteria, the components of the final IDEAs intervention included a practice briefing, audit and feedback with technical support, practice-endorsed reminders (delivered in person, by phone and letter), and an information leaflet targeting key attitudinal and knowledge barriers (Table 3). Following consultation with the national DRS programme, we decided to include the self-registration and consent form with the GP-endorsed letter and information leaflet, to provide patients with another way to participate in the programme.

\section{Intervention design}

Following review by NALA and the PPI panel, some changes were made to the wording of the messages and the overall design of the intervention materials. For example, we reduced the amount of information provided on the instruction page of the information leaflet and emphasised 'friendliness' and helpfulness of RetinaScreen staff. RetinaScreen gave permission to use their logo to make the information leaflet potentially more familiar to patients if they had already received materials from the programme. It also ensures both patients and HCPs are aware the intervention aligns with the national programme. Materials were also designed using a colour scheme similar to that used by RetinaScreen (Additional files 10, 11 and 12).

\section{Step 4: How can behaviour change be measured and understood? \\ Logic model}

The intervention is expected to work by enabling professional behaviour change (financial resource) and improving their knowledge of non-attendance. Patient behaviour is expected to change by using HCPs to prompt and persuade patients to attend screening, altering beliefs or attitudes about the consequences of screening, and enhancing selfefficacy by offering support and information about how to participate in screening (Fig. 2). Relevant theories which may explain the mechanism of action, include the Health Belief Model [81], Protection Motivation Theory [82], the Theory of Planned Behaviour [83] (patient behaviour), and control theory [84] (professional behaviour), along with macro level theories, Systems Theory, Institutional Theory, and Contingency Theory [85]. These will be explored further through the process evaluation embedded in the feasibility trial of the intervention [86].

\section{Discussion}

This paper outlines the development of a multifaceted, multi-level implementation intervention using a systematic process combining theory, collaboration with multiple stakeholders, and existing evidence of effectiveness of interventions, using the case of screening uptake as an example. Enhancing the implementation of screening programmes is an important issue not only in Ireland but internationally, as evidenced by suboptimal uptake reported in different countries [13-16]. Given the efficacy of screening, and the resources invested in these programmes, it is important to maximise attendance. Non-attendance is also costly; within a UK primary care organisation, missed DRS appointments were retrospectively calculated to cost $£ 78,259$ per annum 


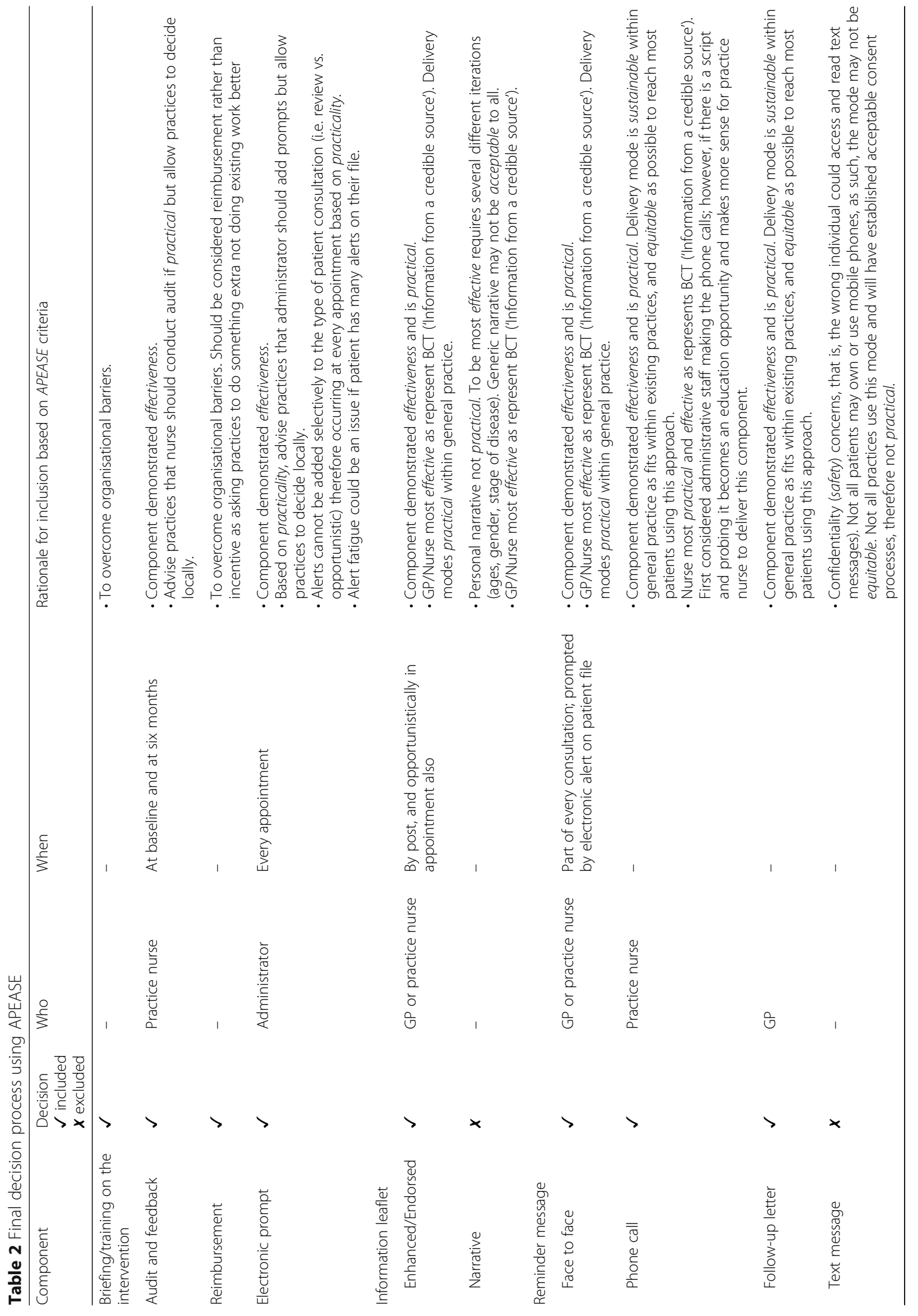




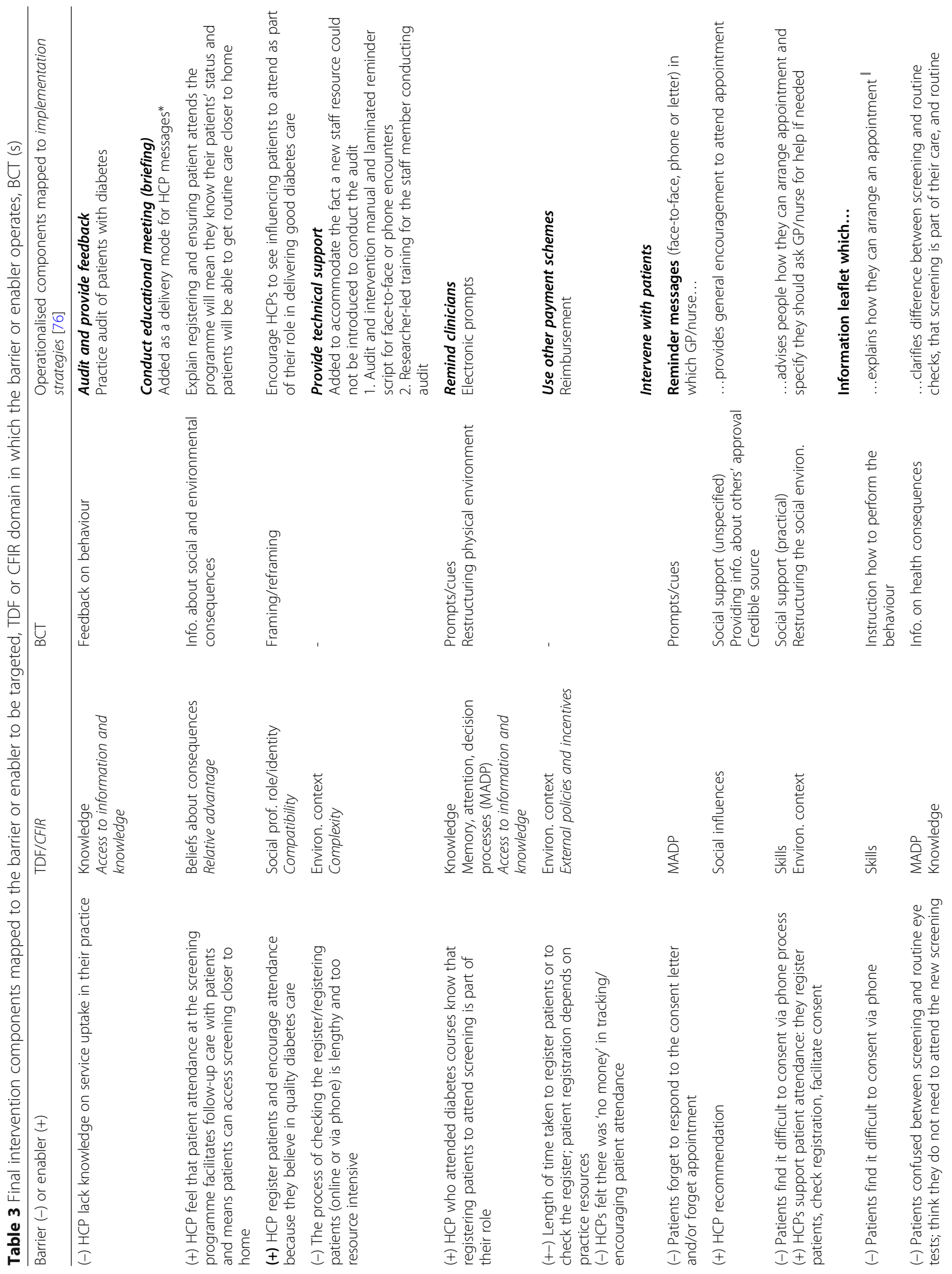




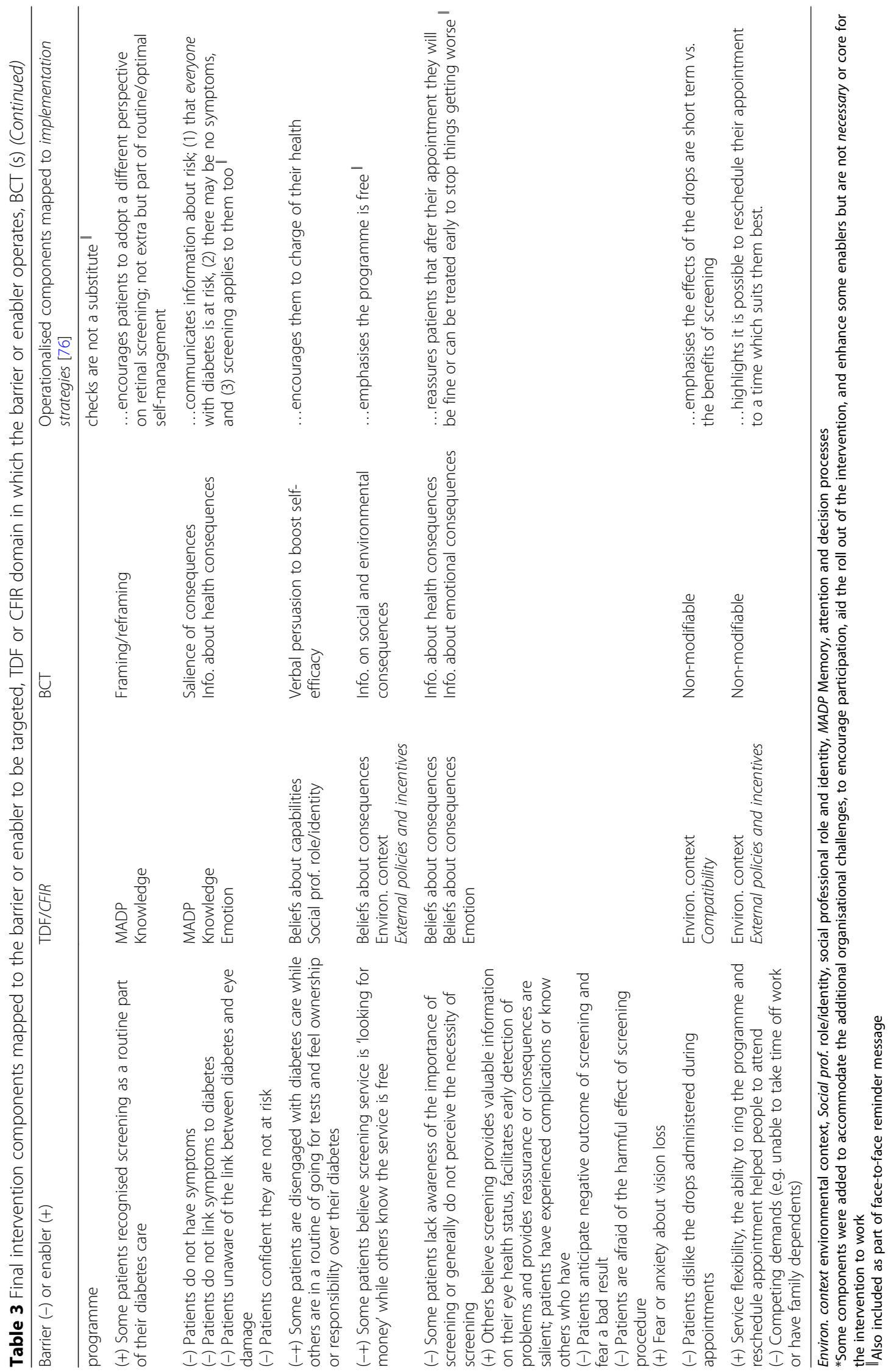




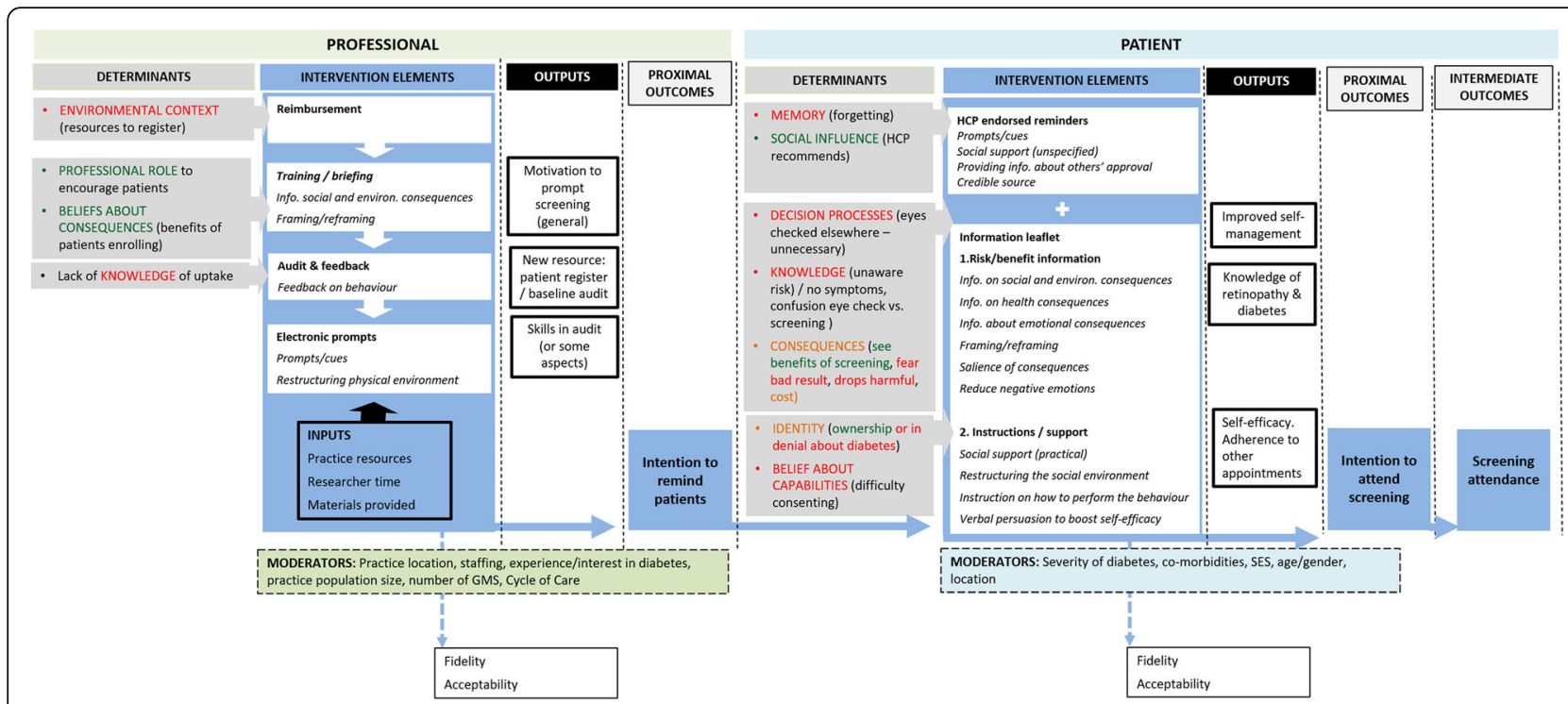

Fig. 2 Logic model of the professional and patient-level intervention mapped to determinants (barriers and enablers according to the Theoretical Domains Framework) and BCTs to improve screening attendance

[87]. To improve DRS uptake, our intervention will target both professional behaviour (using practice briefing, training, reimbursement, audit and feedback, and prompts) and patient behaviours (using practice-endorsed reminder messages and information leaflet). Our process outlines how to develop a theory-driven intervention while involving stakeholders throughout and integrating their perspectives and preferences.

To our knowledge, our intervention to improve DRS uptake is one of few targeting both professionals and patients to be delivered through primary care. The advent of international and national reforms to strengthen care delivery in the community means the role of primary care in chronic disease management is increasingly important. Primary care HCPs have an ongoing contact with people with diabetes and may have the potential to reach vulnerable patients who have stopped attending specialist care [88]. GP endorsement has been used effectively to increase uptake of cancer screening [89-91]. The current intervention serves as an example of how the doctor-patient relationship [24, 25], and existing local services (i.e. primary care practices), may be leveraged to support the implementation of population-based programmes.

\section{Strengths and limitations of the study}

This paper clearly documents the development process and the decisions on intervention content and mode of delivery. We outline how BCTs were operationalised to form intervention components. While the APEASE criteria are often used to contextualise an intervention, few studies apply it systematically [92]. We faced initial challenges when applying the criteria. We surveyed members of the research team asking them to rate each shortlisted component based on APEASE. However, we found they were less comfortable applying some criteria, for example, effectiveness. To address this, we carried out a rapid evidence review and conducted an open discussion whereby members were informed of the evidence and could contribute their different expertise to different criteria. We specified the data sources which were ultimately used to populate each criterion and inform our decision on intervention components. A further strength is the multidisciplinary collaborative approach to develop the intervention. In line with MRC recommendations [62], we ensured that end users, namely people with diabetes and primary care HCPs, were involved at different steps throughout the study. Firstly, interviews with people with diabetes and HCP interviews were used to identify barriers and enablers specific to the Irish context. As these were consistent with factors identified in the international review, we are confident that the intervention targets salient barriers and enablers. Secondly, a two-stage consensus process involved professionals and patients in co-creating the intervention, paying particular attention to how components would work in real world practice. Thirdly, our research team is multidisciplinary blending expertise in implementation research and practice, comprising academic GPs and ophthalmologist, 
health services researchers, an epidemiologist, economist, and behavioural scientist. Consultation with the national DRS programme ensured the feasibility and 'fit' of the intervention with existing processes. Lastly, we established a PPI panel, which enabled patients to be further involved in finalising the study materials. A final strength is that our intervention incorporates a number of BCTs identified as 'missed opportunities' by the Cochrane review, that is, BCTs which theoretically mapped to important barriers but were infrequently used in existing approaches to improve uptake [55]. Specifically, we included BCTs which addressed emotional barriers to screening attendance such as fear of a bad result following screening.

The intervention has some limitations. The intervention is delivered through primary care and largely relies on endorsement from primary care HCPs. While patients with type 2 diabetes should attend their GP regularly, some individuals may have infrequent or no contact with their primary care provider [93], for example, patients who are disengaged with health services and self-management more generally, due to diabetesspecific distress [94] and the phenomenon of 'diabetes burnout' [95]. Furthermore, not all patients may heed messages delivered through their GP, instead favouring messages communicated by friends or family. Support from family members was an enabler identified both in the international literature [25] and in our patient interviews. The influence of family and friends may be possible to emulate through personal, narrative-based leaflets. There is some evidence they can increase intention to attend [96], improve attitudes towards [97], and increase uptake of colorectal screening [98]. While a narrative approach was proposed as an element of the IDEAs intervention, this was ultimately discounted as there were mixed opinions about the most feasible mode of delivery and whether a generic narrative would be acceptable and effective for different groups of patients. Given the diverse profile of people with diabetes that multiple versions (photos, messages) of any leaflet may be important to enhance effectiveness, this approach may be more feasible when the target demographic is reasonably homogenous.

The intervention may need to be adapted for certain population subgroups. As part of the process evaluation, we will pay due attention to fidelity and adaptations (e.g. delivery mode) and whether patients considered the intervention appropriate for them. For example, while NALA reviewed our study materials such that we confident they are readable and accessible for the general population, we acknowledge this intervention does not address language barriers and literacy challenges in population subgroups. Language was an issue identified in the Cochrane review [25]. In Ireland, over $18 \%$ of adults (and 28\% of adults aged 55-65) are at or below Level 1 on the literacy scale [99].

Certain factors may affect how feasible it is for our implementation intervention to be applied in this context. Primary care is diverse in terms of team composition, organisational structure, size, and workflow [100]. Time constraints and workload [101], physician communication style [102], competencies and knowledge [101, 102], protocols to structure care [101], and unclear division of labour $[101,103]$ may present barriers to implementation.

That some suggestions fell outside the scope of our study indicates there may be a need for broader, systemlevel changes to address some of the prevailing challenges in relation to screening attendance (e.g. accessibility/transport and the limited reach of information campaigns). Our intervention does simulate some system-level changes, but at the level of primary care practices, e.g. audit and feedback. As part of the pilot trial, practices will record the reason patients did not attend screening [86]. This information, together with qualitative research with patients as part of the process evaluation, will allow us to explore factors which potentially moderate the effect of the intervention (see examples Fig. 2). It may allow us to explore the reasons for different behaviours, including outstanding issues with screening attendance which are not addressed by the current intervention.

\section{Implications}

We identified a number of challenges during the development process which have broader methodological relevance for implementation science, namely, challenges with respect to applying the TDF/BCT structure; challenges using coproduction (i.e. tensions between theoryinformed suggestions and those suggested by stakeholders); the utility of using both TDF and CFIR; and the potential and feasibility of applying the APEASE criteria systematically. These elements are relevant for those developing interventions beyond the DRS context.

While application of the TDF and subsequent mapping to BCTs was useful to identify theory-informed approaches to target barriers and facilitators, this process was not always straightforward. In some cases, the TDF/ $\mathrm{BCT}$ structure needed to be applied flexibly. For example, HCP interviews were used to inform the 'Skills' domain at the patient level (i.e. patients were not always able to contact or register with the screening programme due to poor IT literacy). Sometimes, multiple TDF domains applied to a specific barrier or facilitator, whereupon multiple domains were applied. For example, patients who recognised screening as a routine part of their diabetes care would attend; this facilitator could be 
coded as 'Memory and decision processes', 'Knowledge', or 'Goals'. There were instances where BCTs deemed appropriate to target a barrier or facilitator did not necessarily map to the corresponding TDF domain. Drawing on the input of researchers and academic GPs, in conjunction with an evidence review, was key to enable the TDF/BCT framework to be applied flexibly and determine which operationalised BCTs 'made sense'. Mapping to TDF domains yielded several possible BCTs, but not all BCTs were relevant, applicable or appropriate for the behaviour in question and context of interest. In this scenario, we found the stepped process of stakeholder involvement was essential to move beyond the TDF/ BCT matrix and to help us make decisions about intervention components which would not be worth pursuing based on acceptability and feasibility concerns. Ultimately, while it was useful to draw on theory and the structure afforded by TDF/BCT, in order to ground our initial intervention components and select the content and delivery mode relevant for the specific context (i.e. primary care), it was crucial to bear the real world context for the intervention and the users in mind.

Our approach also highlights potential challenges of utilising coproduction in intervention development. To involve people with diabetes and HCPs, we used a twostage consensus approach, collecting both quantitative and qualitative data and using a validated instrument to assess acceptability and feasibility [79]. To avoid overly influencing our participants, discussions were semistructured. This allowed them to reflect on the acceptability and feasibility of a long list of potential operationalised BCTs. However, this format also presented tensions at different steps of the process. Firstly, some end users made suggestions which fell outside of study scope or were not evidence-based; this may have reflected the fact participants were not constrained by a more structured format such as Nominal Group Technique or Delphi [104]. As suggested by Powell et al., there is value in presenting stakeholders with evidence-based options and asking them to supplement these based on their own expertise [30]. Deciding how to manage conflicts between, and prioritise, different sources of knowledge (e.g. evidence review vs. tacit knowledge and preferences of stakeholders) is recognised as important during intervention design [64]. However, there is little guidance about how best to balance these different sources. Secondly, integrating the contributions of the different groups across our process was a key challenge, particularly as professional and patient preferences did not always align. Ultimately, we resolved to make evidence-based decisions, incorporating a final check to ensure we addressed salient theoretical domains (barriers and facilitators), and weighing the contributions of patients and professionals according to the nature of their feedback, for example, professional feedback on issues of feasibility (e.g. reminder delivery mode), and patient feedback on issues of acceptability (reminder messages) were given more weight. Given some of the challenges highlighted by the current study, future studies should consider how to structure and sequence user involvement. This could be done by incorporating final 'checks' of user suggestions to check whether these are in line with theory or existing evidence or seeking the input of users on theory-informed intervention elements that have been designed by researchers. Future studies should consider how best to strike a balance between (a) thoroughness of end-user involvement whereby open selection from a long list of suggestions gives users more scope to shape and cocreate the intervention and (b) the efficiency of using a more structured approach such as providing specific examples of interventions and asking for feedback [105].

A plethora of frameworks exist for intervention development and investigating behavioural influences [58, 106]. Our study drew on the relative strengths of different frameworks for different purposes. As in other studies [70], we found utilising CFIR together with the TDF useful to elaborate on implementation determinants in the outer and inner setting which fall within the TDF domain 'environmental context' and help translate barriers and enablers into practical approaches to implementation [107]. Factors not addressed by our intervention may moderate intervention effectiveness; we will use this information to guide the type of data we collect as part of the process evaluation. Our approach highlights the value of recording organisational factors.

Our study demonstrates the potential and feasibility of applying the APEASE framework in a systematic way. That is, since members of the research team lacked specific knowledge about effectiveness of intervention components and delivery modes, we conducted a rapid evidence review, allowing the team to focus on other criteria (affordability, equity, sustainability) where their expertise was most valuable.

\section{Conclusion}

This paper outlines a comprehensive process involving intervention users to develop a multifaceted, multi-level implementation intervention to improve the uptake of a national DRS programme. By systematically applying theory, collaborating with multiple stakeholders and reviewing the evidence base, we are confident we have developed an intervention which is more likely to be feasible to deliver in primary care and acceptable to both professionals and patients. We have used the example of an intervention to improve DRS uptake to illustrate an approach to integrate theory with user involvement and some of the associated challenges. Our final intervention 
is designed to fit within the primary care practice workflow, leveraging the trusted professional-patient relationship and familiarity of local services to enhance implementation of a national population-level screening programme. Though developed using robust methods, the effectiveness of the intervention is not guaranteed. The feasibility of the intervention and study procedures will be assessed as part of a pilot cluster randomised trial with a view to progressing to a definitive trial. This will ultimately determine whether IDEAs is a clinically and cost effective intervention to enhance the implementation of a national DRS programme and improve health outcomes for patients with diabetes.

\section{Supplementary information}

Supplementary information accompanies this paper at https://doi.org/10. 1186/s13012-020-00982-4.

\section{Additional file 1. Topic guides \\ Additional file $\mathbf{2}$ Table S1. Theoretical Domains Framework: definitions and coding structure developed by Graham-Rowe et al. [26]. \\ Additional file 3. Questionnaire. \\ Additional file 4. PubMed search strategy. \\ Additional file 5: Table S2. Patient characteristics.}

Additional file 6: Table S3. a. Modifiable patient-level barriers and enablers and corresponding TDF mapped to BCTs. b. Modifiable professional-level barriers and enablers and corresponding TDF mapped to BCTs based on published expert consensus about effectiveness for behaviour change $[5,6]$ and the mapping matrix constructed by Lawrenson et al. [7]. b Modifiable professional-level barriers and enablers and corresponding TDF mapped to BCTs based on published expert consensus about effectiveness for behaviour change $(1,2)$ and the mapping matrix constructed by Lawrenson et al HTA. (3) a Modifiable patient-level barriers and enablers and corresponding TDF mapped to BCTs based on published expert consensus about effectiveness for behaviour chang e[5, 6] and the mapping matrix constructed by Lawrenson et al. [7]. b Modifiable professional-level barriers and enablers and corresponding TDF mapped to BCTs based on published expert consensus about effectiveness for behaviour change $(1,2)$ and the mapping matrix constructed by Lawrenson et al. HTA (3).

Additional file 7: Table S4. Organisational factors identified from health professional and patient interviews, coded according to CFIR and TDF.

Additional file 8: Table S5. a Patient-level barriers or enablers mapped to TDF, BCT and operationalisation. b Professional-level barriers or enablers mapped to TDF, BCT and operationalisation. c. Organisational level barriers or enablers mapped to TDF, BCT and operationalisation.

Additional file 9: Figure S1. a Ways to encourage patients to attend (practice led). b Ways to encourage patients to attend (narrative led). c Ways to encourage patients to attend (other ideas). d Ways to encourage professionals to prompt patients about screening (feedback). e Ways to encourage professionals to prompt patients about screening (feedback). $f$ Ways to encourage professionals to prompt patients about screening (other ideas).

Additional file 10. Script.

Additional file 11. Reminder letter.

Additional file 12. Patient information leaflet.

\section{Abbreviations}

BCTs: Behaviour change techniques; CFIR: Consolidated Framework for Implementation Research; DR: Diabetic retinopathy; DRS: Diabetic retinopathy screening; GP: General practitioner; HCP: Health care professional;
IDEAs: Improving Diabetes Eye screening Attendance; MADP: Memory, attention, decision processes; TDF: Theoretical Domains Framework

\section{Acknowledgements}

We wish to acknowledge Dr Marsha Tracey who conducted the patient interviews and Dr Kate O'Neill who conducted some health care professional interviews.

\section{Authors' contributions}

SMH conceived the study. SMH, FR, ER, EP, and JB conducted the consensus process. SMH and FR analysed the data. FL advised on the application of behaviour change theory and the selection of behaviour change techniques. SMH, FR, PMK, SS, and MM took part in the APEASE decision process. CB advised on the content and wording of the intervention materials. FR drafted the manuscript, then circulated among all authors for comments and revision. All authors read and approved the final manuscript.

\section{Funding}

This study is funded under the Health Research Board Definitive Interventions and Feasibility Awards (DIFA-2017-006) awarded to Dr Sheena McHugh in 2017. The funding body has no role in the study and collection, analysis, and interpretation of data and in writing the manuscript.

\section{Availability of data and materials}

Not applicable.

\section{Ethics approval and consent to participate}

Ethical approval for this study was obtained from the Irish College of General Practitioners (ICGP) in April 2019. The IDEAs study will be conducted in accordance with the principals of good clinical practice (GCP), and all site personnel have undergone training in GCP. The protocol and any amendments have been, and will be in the future, reviewed by ICGP and the Clinical Research Facility-Cork.

\section{Consent for publication}

Not applicable

\section{Competing interests}

The authors declare that they have no competing interests.

\section{Author details}

${ }^{1}$ School of Public Health, University College Cork, Western Gateway Building, Western Rd, Cork, Ireland. ${ }^{2}$ Department of General Practice, University College Cork, Cork, Ireland. ${ }^{3}$ Centre for Behaviour Change, University College London, London, England. ${ }^{4}$ Department of General Practice, Royal College of Surgeons of Ireland, Dublin, Ireland. ${ }^{5}$ Department of Economics, Cork University Business School, University College Cork, Cork, Ireland.

Received: 14 October 2019 Accepted: 12 March 2020

Published online: 19 May 2020

\section{References}

1. World Health Organisation (WHO). Global report on diabetes. France: WHO Press; 2016.

2. Sivaprasad S, Gupta B, Crosby-Nwaobi R, Evans J. Prevalence of diabetic retinopathy in various ethnic groups: a worldwide perspective. Surv Ophthalmol. 2012:57(4):347-70.

3. Fong DS, Aiello L, Gardner TW, King GL, Blankenship G, Cavallerano JD, Ferris FL 3rd, Klein R. Retinopathy in diabetes. Diabetes Care. 2004;27(Suppl 1):S84-7.

4. Yau JWY, Rogers SL, Kawasaki R, Lamoureux EL, Kowalski JW, Bek T, Chen SJ, Dekker JM, Fletcher A, Grauslund J, et al. Global prevalence and major risk factors of diabetic retinopathy. Diabetes Care. 2012;35(3):556.

5. Tracey ML, McHugh SM, Buckley CM, Canavan RJ, Fitzgerald AP, Kearney PM The prevalence of Type 2 diabetes and related complications in a nationally representative sample of adults aged 50 and over in the Republic of Ireland. Diabet Med. 2015

6. Kelliher C, Kenny D, O'Brien C. Trends in blind registration in the adult population of the Republic of Ireland 1996-2003. Br J Ophthalmol. 2006; 90(3):367-71. 
7. Cheung N, Mitchell P, Wong TY. Diabetic retinopathy. Lancet. 2010; 376(9735):124-36.

8. Chew EY, Ferris FL 3rd, Csaky KG, Murphy RP, Agron E, Thompson DJ, Reed GF, Schachat AP. The long-term effects of laser photocoagulation treatment in patients with diabetic retinopathy: the early treatment diabetic retinopathy follow-up study. Ophthalmology. 2003;110(9):1683-9.

9. Jones S, Edwards RT. Diabetic retinopathy screening: a systematic review of the economic evidence. Diabet Med. 2010;27(3):249-56.

10. American Diabetes Association. Standards of medical care in diabetes 2016. Diabetes Care. 2017:40(Suppl. 1):S128-9.

11. Irish College of General Practitioners (ICGP). A practical guide to integrated type 2 diabetes care. Dublin: Irish College of General Practitioners; 2016.

12. National Institute for Health and Care Excellence (NICE). Type 2 diabetes in adults: management. London: National Institute for Health and Care Excellence; 2015.

13. Zwarenstein M, Shiller SK, Croxford R, Grimshaw JM, Kelsall D, Paterson JM Laupacis A, Austin PC, Tu K, Yun L, et al. Printed educational messages aimed at family practitioners fail to increase retinal screening among their patients with diabetes: a pragmatic cluster randomized controlled trial [ISRCTN72772651]. Implement Sci. 2014;9(1):87.

14. Millett C, Dodhia H. Diabetes retinopathy screening: audit of equity in participation and selected outcomes in South East London. J Med Screen. 2006;13(3):152-5.

15. Paz SH, Varma R, Klein R, Wu J, Azen SP. Noncompliance with vision care guidelines in Latinos with type 2 diabetes mellitus: the Los Angeles Latino Eye Study. Ophthalmology. 2006;113(8):1372-7.

16. Saadine JB, Fong DS, Yao J. Factors associated with follow-up eye examinations among persons with diabetes. Retina. 2008;28(2):195-200.

17. Benoit SR, Swenor B, Geiss LS, Gregg EW, Saaddine JB. Eye care utilization among insured people with diabetes in the U.S., 2010-2014. Diabetes Care. 2019:42(3):427-33.

18. Cavan D, Makaroff $L$, da Rocha FJ, Sylvanowicz M, Ackland P, Conlon J, Chaney D, Malhi A, Barratt J. The diabetic retinopathy barometer study: global perspectives on access to and experiences of diabetic retinopathy screening and treatment. Diabetes Res Clin Pract. 2017;129:16-24.

19. Health Service Executive. Performance profile January - March 2019. Quarterly report. Dublin: HSE; 2019.

20. Scanlon PH. The English national screening programme for sightthreatening diabetic retinopathy. J Med Screen. 2008;15(1):1-4.

21. Gulliford MC, Dodhia H, Chamley M, McCormick K, Mohamed M, Naithani S, Sivaprasad S. Socio-economic and ethnic inequalities in diabetes retinal screening. Diabet Med. 2010;27(3):282-8.

22. Hwang J, Rudnisky C, Bowen S, Johnson JA. Socioeconomic factors associated with visual impairment and ophthalmic care utilization in patients with type II diabetes. Can J Ophthalmol. 2015;50(2):119-26.

23. Kliner M, Fell G, Gibbons C, Dhothar M, Mookhtiar M, Cassels-Brown A. Diabetic retinopathy equity profile in a multi-ethnic, deprived population in Northern England. Eye. 2012;26(5):671-7.

24. van Eijk KN, Blom JW, Gussekloo J, Polak BC, Groeneveld Y. Diabetic retinopathy screening in patients with diabetes mellitus in primary care: Incentives and barriers to screening attendance. Diabetes Res Clin Pract. 2012;96(1):10-6.

25. Graham-Rowe E, Lorencatto F, Lawrenson JG. Barriers to and enablers of diabetic retinopathy screening attendance: a systematic review of published and grey literature; 2018

26. Liu Y, Zupan NJ, Shiyanbola OO, Swearingen R, Carlson JN, Jacobson NA, Mahoney JE, Klein R, Bjelland TD, Smith MA. Factors influencing patient adherence with diabetic eye screening in rural communities: a qualitative study. PLoS One. 2018;13(11):e0206742.

27. Proctor EK, Powell BJ, McMillen JC. Implementation strategies: recommendations for specifying and reporting. Implement Sci. 2013;8(1):139.

28. Aarons GA, Hurlburt M, Horwitz SM. Advancing a conceptual model of evidence-based practice implementation in public service sectors. Admin Pol Ment Health. 2011;38(1):4-23.

29. Baker R, Camosso-Stefinovic J, Gillies C, Shaw EJ, Cheater F, Flottorp S, Robertson N, Wensing M, Fiander M, Eccles MP, et al. Tailored interventions to address determinants of practice. Cochrane Database Syst Rev. 2015;(4): Cd005470.

30. Powell BJ, Beidas RS, Lewis CC, Aarons GA, McMillen JC, Proctor EK, Mandell DS. Methods to improve the selection and tailoring of implementation strategies. J Behav Health Serv Res. 2017;44(2):177-94.
31. Weiner BJ, Lewis MA, Clauser SB, Stitzenberg KB. In search of synergy: strategies for combining interventions at multiple levels. J Natl Cancer Inst Monogr. 2012;2012(44):34-41.

32. Grol R, Grimshaw J. From best evidence to best practice: effective implementation of change in patients' care. Lancet. 2003;362(9391):1225-30.

33. International Diabetes Federation (IDF). IDF Diabetes Atlas. 7th ed: International Diabetes Federation (IDF); 2015.

34. Stratton IM, Adler Al, Neil HA, Matthews DR, Manley SE, Cull CA, Hadden D, Turner RC, Holman RR. Association of glycaemia with macrovascular and microvascular complications of type 2 diabetes (UKPDS 35): prospective observational study. BMJ. 2000;321(7258):405-12.

35. Legorreta AP, Hasan MM, Peters AL, Pelletier KR, Leung K-M. An intervention for enhancing compliance with screening recommendations for diabetic retinopathy: a bicoastal experience. Diabetes Care. 1997;20(4):520.

36. Lee SJ, McCarty CA, Sicari C, Livingston PM, Harper CA, Taylor HR, Keeffe JE. Recruitment methods for community-based screening for diabetic retinopathy. Ophthalmic Epidemiol. 2000;7(3):209-18.

37. Buonaccorso KM. Diabetic retinopathy screening: a clinical quality improvement project. J Healthc Qual. 1999;21(6):35-38, 46.

38. Brooks RJ, Legorreta AP, Silver A, Fabius R, Krakovitz J. Implementing guidelines for eye care of diabetic patients: results from an $\mathrm{HMO}$ intervention study. Am J Manag Care. 1996;2:365-9.

39. Burnett S, Hurwitz B, Davey C, Ray J, Chaturvedi N, Salzmann J, Yudkin JS. The implementation of prompted retinal screening for diabetic eye disease by accredited optometrists in an inner-city district of North London: a quality of care study. Diabet Med. 1998;15(S3):S38-43.

40. Lawrenson JG, Graham-Rowe E, Lorencatto F, Burr J, Bunce C, Francis JJ, Aluko P, Rice S, Vale L, Peto T, et al. Interventions to increase attendance for diabetic retinopathy screening. Cochrane Database Syst Rev. 2018;1.

41. Zhang X, Norris SL, Saadine J, Chowdhury FM, Horsley T, Kanjilal S, Mangione CM, Buhrmann R. Effectiveness of interventions to promote screening for diabetic retinopathy. Am J Prev Med. 2007;33(4):318-35.

42. Tricco AC, Ivers NM, Grimshaw JM, Moher D, Turner L, Galipeau J, Halperin I, Vachon B, Ramsay T, Manns B, et al. Effectiveness of quality improvement strategies on the management of diabetes: a systematic review and metaanalysis. Lancet. 2012;379(9833):2252-61.

43. Basch CE, Walker EA, Howard CJ, Shamoon H, Zybert P. The effect of health education on the rate of ophthalmic examinations among African Americans with diabetes mellitus. Am J Public Health. 1999;89(12):1878-82.

44. Ellish NJ, Royak-Schaler R, Higginbotham EJ. Tailored and targeted interventions to encourage dilated fundus examinations in older African Americans. Arch Ophthalmol. 2011;129(12):1592-8.

45. Lafata JE, Baker AM, Divine GW, McCarthy BD, Xi H. The use of computerized birthday greeting reminders in the management of diabetes. J Gen Intern Med. 2002;17(7):521-30.

46. Prela CM, Smilie JG, McInerney MJ, Harwell TS, Helgerson SD. Direct mail intervention to increase retinal examination rates in Medicare beneficiaries with diabetes. Am J Med Qual. 2000;15(6):257-62.

47. Halbert RJ, Leung KM, Nichol JM, Legorreta AP. Effect of multiple patient reminders in improving diabetic retinopathy screening. A randomized trial. Diabetes Care. 1999:22(5):752-5.

48. Koshy E, Car J, Majeed A. Effectiveness of mobile-phone short message service (SMS) reminders for ophthalmology outpatient appointments: observational study. BMC Ophthalmol. 2008;8(1):9.

49. Chen T, Zhu W, Tang B, Jin L, Fu H, Chen Y, Wang C, Zhang G, Wang J, Ye $T$, et al. A mobile phone informational reminder to improve eye care adherence among diabetic patients in Rural China: a randomized controlled trial. Am J Ophthalmol. 2018;194:54-62.

50. Iveta O, Agnes B. Diabetic eye screening clinics: to attend or not to attend! that is the question. Diabetes Update; 2018.

51. Anderson RM, Musch DC, Nwankwo RB, Wolf FM, Gillard ML, Oh MS, Fitzgerald JT, Johnson MW, Hiss RG. Personalized follow-up increases return rate at urban eye disease screening clinics for African Americans with diabetes: results of a randomized trial. Ethn Dis. 2003;13(1):40-6.

52. Bush K, Thomas R, Raymond NT, Sankar S, Barker PJ, O'Hare JP. Cluster randomised controlled trial evaluation of a Link Worker-delivered intervention to improve uptake of diabetic retinopathy screening in a South Asian population. Diab Vasc Dis Res. 2014;11(4):294-7.

53. Zangalli CS, Murchison AP, Hale N, Hark LA, Pizzi LT, Dai Y, Leiby BE, Haller JA. An education- and telephone-based intervention to improve follow-up 
to vision care in patients with diabetes: a prospective, single-blinded, randomized trial. Am J Med Qual. 2016;31(2):156-61.

54. Schnipper JL, Linder JA, Palchuk MB, Yu DT, McColgan KE, Volk LA, Tsurikova R, Melnikas AJ, Einbinder JS, Middleton B. Effects of documentation-based decision support on chronic disease management. Am J Manag Care. 2010; 16(12 Suppl HIT):Sp72-81.

55. Lawrenson JG, Graham-Rowe E, Lorencatto F, Rice S, Bunce C, Francis JJ, Burr JM, Aluko P, Vale L, Peto T, et al. What works to increase attendance for diabetic retinopathy screening? An evidence synthesis and economic analysis. Health Technol Assess. 2018;22(29):1-160.

56. Weiss DM, Casten RJ, Leiby BE, Hark LA, Murchison AP, Johnson D, Stratford S, Henderer J, Rovner BW, Haller JA. Effect of behavioral intervention on dilated fundus examination rates in older african american individuals with diabetes mellitus: a randomized clinical trial. JAMA Ophthalmol. 2015;133(9): 1005-12.

57. Turner KM, Rousseau N, Croot L, Duncan E, Yardley L, O'Cathain A, Hoddinott P. Understanding successful development of complex health and healthcare interventions and its drivers from the perspective of developers and wider stakeholders: an international qualitative interview study. BMJ Open. 2019;9(5):e028756.

58. O'Cathain A, Croot L, Sworn K, Duncan E, Rousseau N, Turner K, Yardley L, Hoddinott P. Taxonomy of approaches to developing interventions to improve health: a systematic methods overview. Pilot Feasibility Stud. 2019; $5: 41$.

59. Dalgetty R, Miller CB, Dombrowski SU. Examining the theory-effectiveness hypothesis: a systematic review of systematic reviews. Br J Health Psychol. 2019;24(2):334-56.

60. Prestwich A, Sniehotta FF, Whittington C, Dombrowski SU, Rogers L, Michie $S$. Does theory influence the effectiveness of health behavior interventions? Meta-analysis. Health Psychol. 2014;33(5):465-74.

61. Curran GM, Mukherjee $S$, Allee E, Owen RR. A process for developing an implementation intervention: QUERI series. Implement Sci. 2008;3(1):17.

62. Craig P, Dieppe P, Macintyre S, Michie S, Nazareth I, Petticrew M. Developing and evaluating complex interventions: the new Medical Research Council guidance. BMJ. 2008;337:a1655.

63. Powell BJ, Fernandez ME, Williams NJ, Aarons GA, Beidas RS, Lewis CC, McHugh SM, Weiner BJ. Enhancing the impact of implementation strategies in healthcare: a research agenda. Front Public Health. 2019;7(3).

64. Rousseau N, Turner KM, Duncan E, O'Cathain A, Croot L, Yardley L, Hoddinott $P$. Attending to design when developing complex health interventions: a qualitative interview study with intervention developers and associated stakeholders. PLoS One. 2019;14(10):e0223615.

65. French SD, Green SE, O'Connor DA, McKenzie JE, Francis JJ, Michie S, Buchbinder R, Schattner P, Spike N, Grimshaw JM. Developing theoryinformed behaviour change interventions to implement evidence into practice: a systematic approach using the Theoretical Domains Framework. Implement Sci. 2012;7:38.

66. Leask CF, Sandlund M, Skelton DA, Altenburg TM, Cardon G, Chinapaw MJM, De Bourdeaudhuij I, Verloigne M, Chastin SFM, on behalf of the GrandStand SS, et al. Framework, principles and recommendations for utilising participatory methodologies in the co-creation and evaluation of public health interventions. Res Involve Engage. 2019;5(1):2.

67. INVOLVE. Briefing note seven: approaches to public involvement in research. In: Briefing notes for researchers: public involvement in NHS, public health and social care research. edn: National Insitute for Health Research (NIHR); 2012.

68. Tracey M, Racine E, Riordan F, McHugh S, Kearney P. Understanding the uptake of a national retinopathy screening programme: an audit of patients with diabetes in two large primary care centres [version 1; peer review: awaiting peer review]. HRB Open Res. 2019;2(17).

69. French SD, McKenzie JE, O'Connor DA, Grimshaw JM, Mortimer D, Francis JJ, Michie S, Spike N, Schattner P, Kent P, et al. Evaluation of a theory-informed implementation intervention for the management of acute low back pain in general medical practice: the IMPLEMENT cluster randomised trial. PLoS One. 2013;8(6):e65471.

70. Tavender EJ, Bosch M, Gruen RL, Green SE, Michie S, Brennan SE, Francis JJ, Ponsford JL, Knott JC, Meares S, et al. Developing a targeted, theoryinformed implementation intervention using two theoretical frameworks to address health professional and organisational factors: a case study to improve the management of mild traumatic brain injury in the emergency department. Implement Sci. 2015;10:74.
71. Hoffmann TC, Glasziou PP, Boutron I, Milne R, Perera R, Moher D, Altman DG, Barbour V, Macdonald H, Johnston M, et al. Better reporting of interventions: template for intervention description and replication (TIDieR) checklist and guide. BMJ. 2014;348.

72. Tracey M, Racine E, Riordan F, McHugh S, Kearney P. Understanding the uptake of a national retinopathy screening programme: an audit of people with diabetes in two large primary care centres [version 3; peer review: 1 approved, 1 approved with reservations]. HRB Open Res. 2019;2(17).

73. McHugh S, Tracey ML, Riordan F, O'Neill K, Mays N, Kearney PM. Evaluating the implementation of a national clinical programme for diabetes to standardise and improve services: a realist evaluation protocol. Implement Sci. 2016;11(1):107.

74. Michie S, Johnston M, Abraham C, Lawton R, Parker D, Walker A. Making psychological theory useful for implementing evidence based practice: a consensus approach. Qual Saf Health Care. 2005;14(1):26.

75. Graham-Rowe E, Lorencatto F, Lawrenson JG, Burr J, Grimshaw JM, Ivers NM, Peto T, Bunce C, Francis JJ. Barriers and enablers to diabetic retinopathy screening attendance: protocol for a systematic review. Syst Rev. 2016;5(1):134.

76. Michie S, Johnston M, Francis J, Hardeman W, Eccles M. From theory to intervention: mapping theoretically derived behavioural determinants to behaviour change techniques. Appl Psychol. 2008;57(4):660-80.

77. Cane J, Richardson M, Johnston M, Ladha R, Michie S. From lists of behaviour change techniques (BCT s) to structured hierarchies: comparison of two methods of developing a hierarchy of BCT s. Br J Health Psychol. 2015;20(1):130-50.

78. Racine E. 'It just wasn't going to be heard': a mixed methods study to compare different ways of involving people with diabetes and healthcare professionals in health intervention research. 2019. In preparation.

79. Weiner BJ, Lewis CC, Stanick C, Powell BJ, Dorsey CN, Clary AS, Boynton MH, Halko H. Psychometric assessment of three newly developed implementation outcome measures. Implement Sci. 2017;12(1):108.

80. Byrne M, O'Connell A, Egan AM, Dinneen SF, Hynes L, O'Hara MC, Holt RIG, Willaing I, Vallis $\mathrm{M}$, Hendrieckx C, et al. A core outcomes set for clinical trials of interventions for young adults with type 1 diabetes: an international, multi-perspective Delphi consensus study. Trials. 2017;18(1):602.

81. Rosenstock IM, Strecher VJ, Becker MH. Social learning theory and the health belief model. Health Educ Q. 1988;15(2):175-83.

82. Rogers RW. A protection motivation theory of fear appeals and attitude change1. J Psychol. 1975;91(1):93-114.

83. Ajzen I. The theory of planned behavior. Organ Behav Hum Decis Process. 1991;50(2):179-211.

84. Carver CS, Scheier MF. Control theory: a useful conceptual framework for personality-social, clinical, and health psychology. Psychol Bull. 1982;92(1):111-35.

85. Birken SA, Bunger AC, Powell BJ, Turner K, Clary AS, Klaman SL, Yu Y, Whitaker DJ, Self SR, Rostad WL, et al. Organizational theory for dissemination and implementation research. Implement Sci. 2017;12(1):62.

86. Riordan FRE, Smith SM, Murphy M, Browne J, Kearney PM, Bradley C, James M, Murphy M, McHugh SM. Feasibility of an implementation intervention to increase attendance at diabetic retinopathy screening: protocol for a cluster randomised pilot trial Pilot and Feasibility Studies (under review); 2019.

87. Waqar S, Bullen G, Chant S, Salman R, Vaidya B, Ling R. Cost implications, deprivation and geodemographic segmentation analysis of non-attenders (DNA) in an established diabetic retinopathy screening programme. Diabetes Metab Syndr. 2012;6(4):199-202.

88. Griffin SJ. Lost to follow-up: the problem of defaulters from diabetes clinics. Diabet Med. 1998;15(Suppl 3):S14-24.

89. Duffy SW, Myles JP, Maroni R, Mohammad A. Rapid review of evaluation of interventions to improve participation in cancer screening services. J Med Screen. 2017;24(3):127-45.

90. Hart AR, Barone TL, Gay SP, Inglis A, Griffin L, Tallon CA, Mayberry JF. The effect on compliance of a health education leaflet in colorectal cancer screening in general practice in central England. J Epidemiol Community Health. 1997;51(2):187-91.

91. Federici A, Giorgi Rossi P, Bartolozzi F, Farchi S, Borgia P, Guastcchi G. The role of GPs in increasing compliance to colorectal cancer screening: a randomised controlled trial (Italy). Cancer Causes Control. 2006;17(1):45-52.

92. Steinmo SH, Michie S, Fuller C, Stanley S, Stapleton C, Stone SP. Bridging the gap between pragmatic intervention design and theory: using behavioural science tools to modify an existing quality improvement programme to implement "Sepsis Six". Implement Sci. 2016;11(1):14. 
93. Ellis DA, McQueenie R, McConnachie A, Wilson P, Williamson AE. Demographic and practice factors predicting repeated non-attendance in primary care: a national retrospective cohort analysis. Lancet Public Health. 2017:2(12):e551-9.

94. Lake AJ, Rees G, Speight J. Clinical and psychosocial factors influencing retinal screening uptake among young adults with type 2 diabetes. Curr Diab Rep. 2018;18(7):41.

95. Abdoli S, Jones DH, Vora A, Stuckey H. Improving diabetes care: should we reconceptualize diabetes burnout? Diab Educ. 2019;45(2):214-24.

96. McGregor LM, von Wagner C, Vart G, Yuen WC, Raine R, Wardle J, Robb KA. The impact of supplementary narrative-based information on colorectal cancer screening beliefs and intention. BMC Cancer. 2015;15(1):162.

97. Wardle J, Williamson S, McCaffery K, Sutton S, Taylor T, Edwards R, Atkin W. Increasing attendance at colorectal cancer screening: testing the efficacy of a mailed, psychoeducational intervention in a community sample of older adults. Health Psychol. 2003;22(1):99-105.

98. Jensen JD, King AJ, Carcioppolo N, Krakow M, Samadder NJ, Morgan S. Comparing tailored and narrative worksite interventions at increasing colonoscopy adherence in adults 50-75: a randomized controlled trial. Soc Sci Med. 2014;104:31-40.

99. Central Statistics Office (CSO). Survey results for Ireland from the OECD's programme for the international assessment of adult competencies. Dublin: Stationery Office; 2012.

100. Lau R, Stevenson F, Ong BN, Dziedzic K, Treweek S, Eldridge S, Everitt H, Kennedy A, Qureshi N, Rogers A, et al. Achieving change in primary care - causes of the evidence to practice gap: systematic reviews of reviews. Implement Sci. 2016;11(1):40.

101. Rushforth B, McCrorie C, Glidewell L, Midgley E, Foy R. Barriers to effective management of type 2 diabetes in primary care: qualitative systematic review. Br J Gen Pract. 2016;66(643):e1 14-27.

102. Nam S, Chesla C, Stotts NA, Kroon L, Janson SL. Barriers to diabetes management: patient and provider factors. Diabetes Res Clin Pract. 2011; 93(1):1-9.

103. Zhang JQ, Van Leuven KA, Neidlinger SH. System barriers associated with diabetes management in primary care. J Nurse Pract. 2012;8(10):822-7.

104. Rankin NM, McGregor D, Butow PN, White K, Phillips JL, Young JM, Pearson $S A$, York S, Shaw T. Adapting the nominal group technique for priority setting of evidence-practice gaps in implementation science. BMC Med Res Methodol. 2016;16(1):110

105. Cederbaum JA, Song A, Hsu H-T, Tucker JS, Wenzel SL. Adapting an evidence-based intervention for homeless women: engaging the community in shared decision-making. J Health Care Poor Underserved. 2014;25(4):1552-70.

106. Birken SA, Rohweder CL, Powell BJ, Shea CM, Scott J, Leeman J, Grewe ME, Alexis Kirk M, Damschroder L, Aldridge WA 2nd, et al. T-CaST: an implementation theory comparison and selection tool. Implement Sci. 2018; 13(1):143.

107. Birken SA, Powell BJ, Presseau J, Kirk MA, Lorencatto F, Gould NJ, Shea CM Weiner BJ, Francis JJ, Yu Y, et al. Combined use of the Consolidated Framework for Implementation Research (CFIR) and the Theoretical Domains Framework (TDF): a systematic review. Implement Sci. 2017;12(1):2.

\section{Publisher's Note}

Springer Nature remains neutral with regard to jurisdictional claims in published maps and institutional affiliations.

\section{Ready to submit your research? Choose BMC and benefit from:}

- fast, convenient online submission

- thorough peer review by experienced researchers in your field

- rapid publication on acceptance

- support for research data, including large and complex data types

- gold Open Access which fosters wider collaboration and increased citations

- maximum visibility for your research: over $100 \mathrm{M}$ website views per year

At BMC, research is always in progress.

Learn more biomedcentral.com/submissions 